\title{
Temperature change in pig rib bone during implant site preparation by low-speed drilling
}

\author{
Sun-Jong KIM${ }^{1}$, Jaeyoung $\mathrm{YOO}^{2}$, Young-Soo KIM${ }^{3}$, Sang-Wan SHIN ${ }^{4}$ \\ 1- DDS, MSD, PhD, Oral and Maxillofacial Surgery, School of Medicine, Ewha Womans University, Seoul, Korea. \\ 2- DDS, MSD, Institute for Clinical Dental Research, Graduate School of Clinical Dentistry, Korea University, Seoul, Korea. \\ 3- DDS, MSD, PhD, Preventive Dentistry, Graduate School of Clinical Dentistry, Korea University, Seoul, Korea. \\ 4- DDS, MPH, PhD, Advanced Prosthodontics, Institute for Clinical Dental Research, Graduate School of Clinical Dentistry, Korea University, Seoul, Korea.
}

Corresponding address: Sun-Jong Kim 911-1 - Mok-dong, Yangcheon-gu, Seoul, Korea - Phone: 82-2-2650-5196 - Fax: 82-2-2650-5764 - sjsj7777@ewha. ac.kr

Received: February 21, 2009 - Modification: October 30, 2009 - Accepted: February 16, 2010

\section{ABSTRACT}

\begin{abstract}
$\mathrm{O}$ bjectives: The purpose of this study was to evaluate the temperature change during lowspeed drilling using infrared thermography. Material and Methods: Pig ribs were used to provide cortical bone of a similar quality to human mandible. Heat production by three implant drill systems (two conventional drilling systems and one low-speed drilling system) was evaluated by measuring the bone temperature using infrared thermography. Each system had two different bur sizes. The drill systems used were twist drill $(2.0 \mathrm{~mm} / 2.5 \mathrm{~mm})$, which establishes the direction of the implant, and finally a $3.0 \mathrm{~mm}$-pilot drill. Thermal images were recorded using the IRI1001 system (Infrared Integrated Systems Ltd.). Baseline temperature was $31 \pm 1^{\circ} \mathrm{C}$. Measurements were repeated 10 times, and a static load of $10 \mathrm{~kg}$ was applied while drilling. Data were analyzed using descriptive statistics. Statistical analysis was conducted with two-way ANOVA. Results and Conclusions: Mean values ( $n=10$ drill sequences) for maximum recorded temperature $\left(\operatorname{Max} \mathrm{T}^{\circ} \mathrm{C}\right)$, change in temperature $\left(\Delta \mathrm{T}^{\circ} \mathrm{C}\right)$ from baseline were as follows. The changes in temperature $\left(\Delta \mathrm{T}^{\circ} \mathrm{C}\right)$ were $1.57^{\circ} \mathrm{C}$ and $2.46^{\circ} \mathrm{C}$ for the lowest and the highest values, respectively. Drilling at $50 \mathrm{rpm}$ without irrigation did not produce overheating. There was no significant difference in heat production between the 3 implant drill systems $(p>0.05)$. No implant drill system produced heat exceeding $47^{\circ} \mathrm{C}$, which is the critical temperature for bone necrosis during low-speed drilling. Low-speed drilling without irrigation could be used during implant site preparation.
\end{abstract}

Key words: Implant drilling. Infrared thermography. Heat production. Bone necrosis.

\section{INTRODUCTION}

Drilling procedures during dental implant site preparation may cause not only mechanical damage to the bone involved but a temperature increase in the bone adjacent to the implant site. Significant temperature increases can result in heat-induced bone injury ${ }^{2}$. Thermonecrosis has been reported in the literatures ${ }^{13-17}$. Eriksson and Albrektsson ${ }^{14}$ (1983) conducted an experiment on the rabbit tibia to evaluate the effects of heat production on bone regeneration. They found that heating the implants in the rabbit tibia to a temperature of $50^{\circ} \mathrm{C}$ for 1 min was enough to cause $30 \%$ of the bone to be resorbed. This was a slow-developing process that extended over a period of 4 weeks. They reported that setting the temperature between 47 and $50^{\circ} \mathrm{C}$ for $1 \mathrm{~min}$ reduced significantly bone formation around the implants, while no significant effects were observed after heating up to $47^{\circ} \mathrm{C}$ for $1 \mathrm{~min}^{13}$. Eriksson and Adell12 (1986) measured temperature change during drilling with a thermocouple, indicating that drilling using the osseointegration technique does not impair bone regeneration due to excessive heat production ${ }^{4,12}$. Watanabe, et al. ${ }^{26}$ (1992) measured heat distribution in bone using thermography and found that the maximum temperature was generated when bone was cut using drills. Based on the result that maximum temperature during drilling was higher without irrigation than with irrigation, they indicated that bone temperature should not exceed the critical temperature without irrigation. Similar results have been reported by Yacker, et al. ${ }^{27}$ (1996). Benington, et al. ${ }^{7}$ (1996) have reported that temperature rises up to $130.1^{\circ} \mathrm{C}$ without irrigation after monitoring changes in bone temperature during the sequence of drilling for implant site preparation by the osseointegration technique using infrared thermography. However, most studies have been performed to investigate temperature change at 
a conventional drilling speed, which is over 1,000 rpm until now. This study evaluated the safety of low-speed drilling at $50 \mathrm{rpm}$ without irrigation due to temperature changes.

\section{MATERIAL AND METHODS}

Pig ribs with a $2.0 \mathrm{~mm}$-thick cortical bone were obtained and sliced into $10 \mathrm{~cm}$-long sections. The main reason for the selection of pig ribs was their superior homogeneity in the thickness of the cortical bone. The cow or pig mandible was considered first. However, the irregular thickness of their cortical bone specimen was a definite disadvantage. Although pig ribs are weaker than the human mandible, they are excellent in homogeneity of the thickness of cortical bone. They were embedded in a resin block, and immobilized to the table. In an attempt to duplicate clinical conditions, the lower half of the specimen was soaked in a water bath at $37 \pm 1^{\circ} \mathrm{C}$, and the upper half of the specimen at a room temperature of $25^{\circ} \mathrm{C}$. Initially, the temperature of the bone was set at $31 \pm 1^{\circ} \mathrm{C}$ (Figure 1 ).

For applying a static load, it was pressed 10 times with the same force as in the operation. About $10 \mathrm{~kg}$ of static load was applied. Bicon implant drill system (Bicon, Boston, MA, USA) was selected as the low-speed drill system in this study. Brånemark drill system (Nobelbiocare, Sweden) and Osstem drill system (Osstem, Seoul, Korea) were used as conventional speed drill systems. Table 1 shows the drilling systems, drill diameter size, irrigation and drill speed used in this study. The measurements were repeated 10 times and $10 \mathrm{~kg}$ of static load was applied while drilling.

To ensure the consistency in the drilling procedure, one operator used a conventional dental handpiece (W\&H, Bürmoos, Austria). The manufacturer's instructions were followed during implant site preparation with low-speed drilling protocol. No irrigation was performed since infrared radiation cannot transmit through water. Consequently, low-speed drilling at $50 \mathrm{rpm}$ with high torque was performed because drilling without irrigation may cause bone necrosis. The temperature was recorded using a digital thermometer IRI1001 system (InfraRed Integrated Systems Ltd., UK) (Figure 2).

To prevent distraction from bur wear, brand-new burs were used. However, since the experiment was repeated 10 times, bur wear might have been a variable as experiments progressed. Brånemark drill system was used only once according to the manufacturer's instructions. The schematic diagram of the experimental implant drill systems is shown in Figure 3.

Data were analyzed using descriptive statistics. Statistical analysis was conducted with two-way ANOVA $(\alpha=0.05)$.

\section{RESULTS}

Drilling at $50 \mathrm{rpm}$ without irrigation did not produce overheating at the tip of the drills; temperatures changes were $1.57^{\circ} \mathrm{C}$ and $2.46^{\circ} \mathrm{C}$ for the lowest and the highest values, respectively.

The drill systems used were a $2.0 \mathrm{~mm}$ twist drill, which establishes the direction of the implant, and a $3.0 \mathrm{~mm}$ pilot drill, which progressively increases the diameter of the site.

As expected, the conventional systems did not increase the temperature of pig cortical bone up to the critical point of $47^{\circ} \mathrm{C}$, which was reported

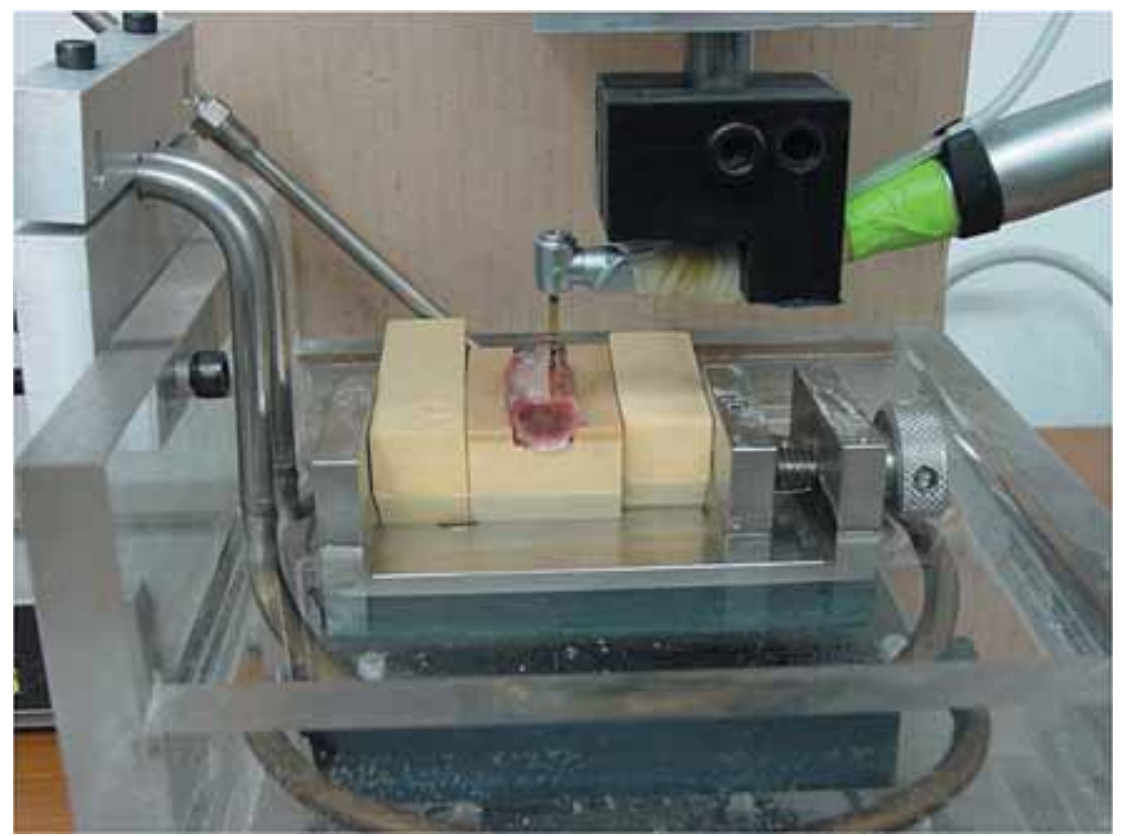

Figure 1- Pig rib immobilized to resin block 


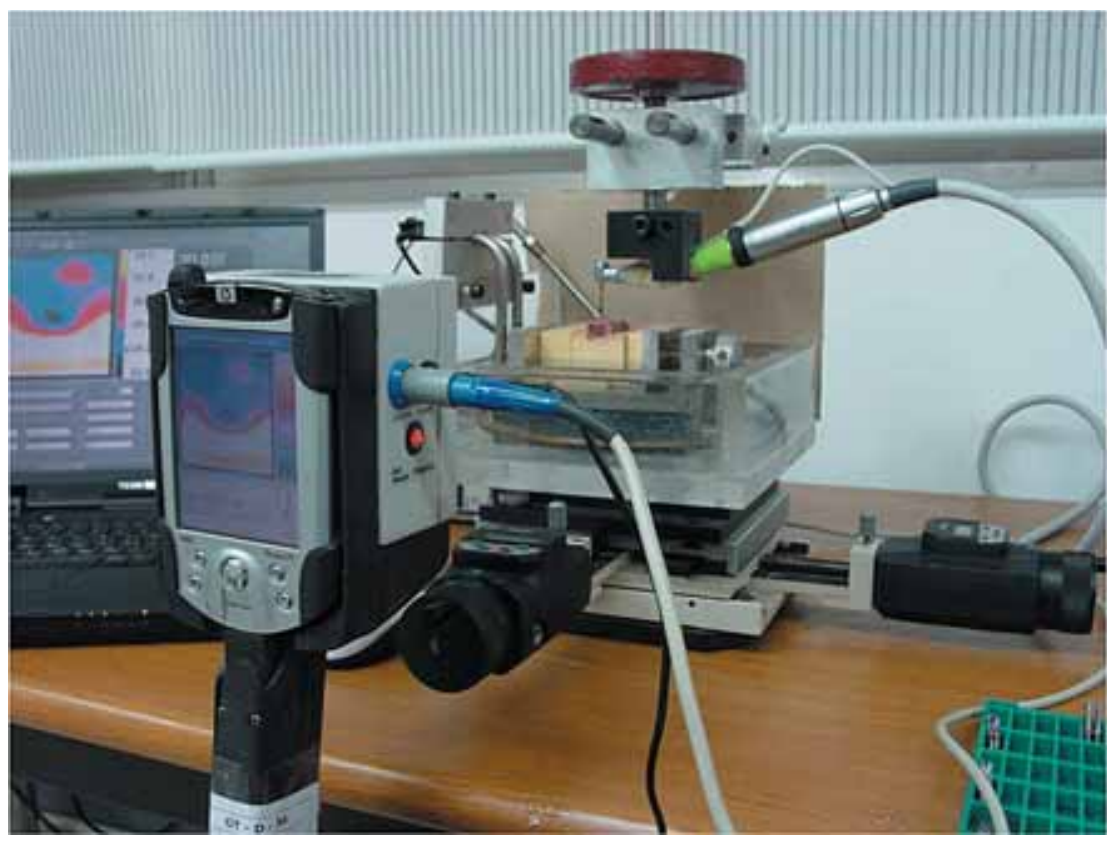

Figure 2- Infrared thermography measured the temperature changes

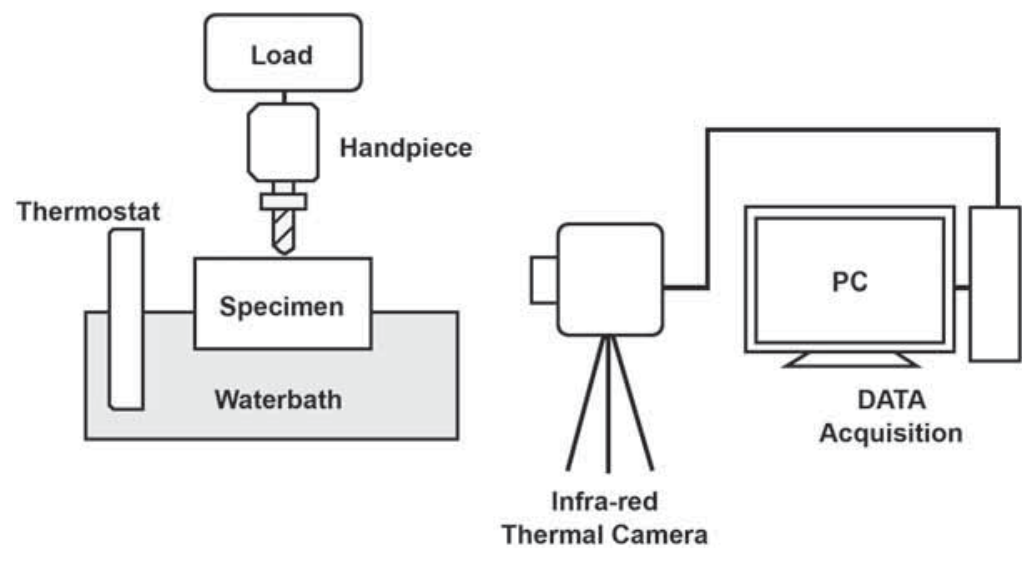

Figure 3- Schematic diagram of the experimental system

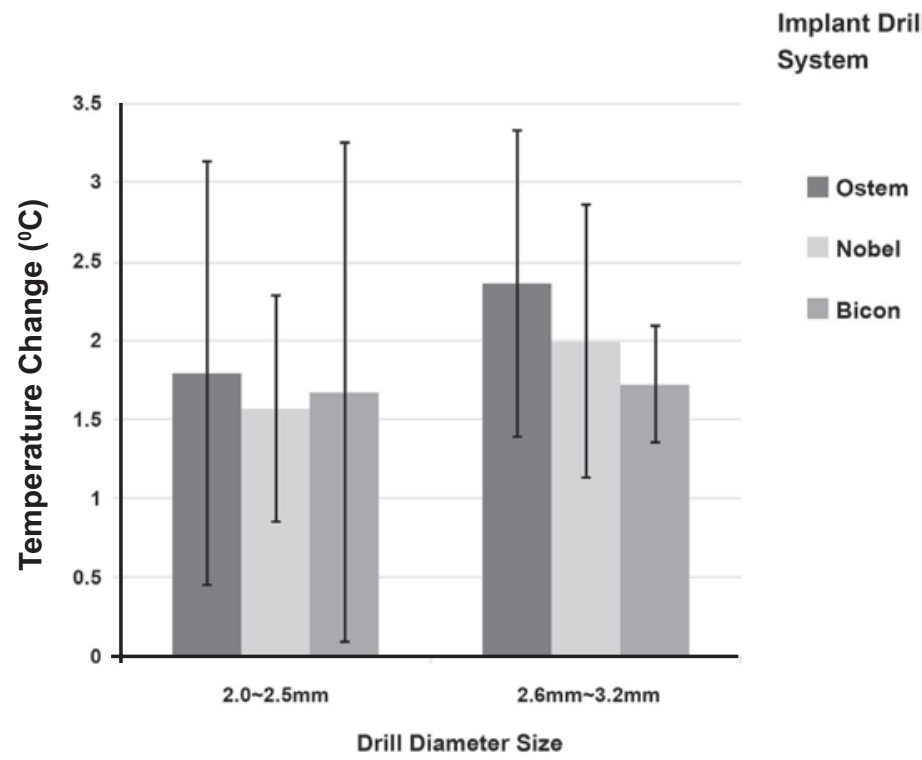

Figure 4- Relationship between drill diameter and bone temperature 
Table 1- Implant drilling systems tested in the study

\begin{tabular}{ccccc}
\hline Implant System & Drill size & Irrigation & \multicolumn{2}{c}{ Drill speed (rpm) } \\
& & & Tested & Recommended \\
\hline Brånemark & $2.0 \mathrm{~mm}, 3.0 \mathrm{~mm}$ & No & 50 & 1,200 \\
Osstem & $2.0 \mathrm{~mm}, 3.0 \mathrm{~mm}$ & No & 50 & 1,200 \\
Bicon & $2.0 \mathrm{~mm}, 3.0 \mathrm{~mm}$ & No & 50 & 50 \\
\hline
\end{tabular}

Table 2- Mean baseline temperature, maxiamum temperature, and temperature difference according to implant drill systems and drill diameter

\begin{tabular}{|c|c|c|c|c|}
\hline System & Diameter $(\mathrm{mm})$ & Mean Baseline Temp. $\left({ }^{\circ} \mathrm{C}\right)$ & Mean Max. Temp. $\left({ }^{\circ} \mathrm{C}\right)$ & Mean $\mathrm{T}\left({ }^{\circ} \mathrm{C}\right)$ \\
\hline \multirow[t]{2}{*}{ Bränemark } & 2 & 30.99 & 32.56 & 1.57 \\
\hline & 3 & 30.59 & 32.58 & 1.99 \\
\hline \multirow[t]{2}{*}{ Osstem } & 2 & 31.74 & 33.53 & 1.79 \\
\hline & 3 & 31.2 & 33.56 & 2.46 \\
\hline \multirow[t]{2}{*}{ Bicon } & 2.5 & 30.61 & 32.28 & 1.67 \\
\hline & 3 & 30.45 & 32.17 & 1.72 \\
\hline
\end{tabular}

by Eriksson, et al. ${ }^{4}$ (2007). The low-speed drilling showed low temperature change as well. The results are summarized in Table 2 .

No implant drill systems produced heat exceeding the critical temperature. There were no significant differences in heat production among the 3 systems. Temperature became higher as drill diameter increased. The implant drill system and the drill diameter were defined as independent factors. There was no significant difference among the 3 implant drill systems $(p>0.05)$. There was statistically significant difference in heat production according to drill diameter $(p<0.05)$. The larger the drill diameter was, the higher the bone temperature because the greater bone volume to be cut created more friction during the drilling procedure. Figure 4 shows the relationship between drill diameter and bone temperature.

\section{DISCUSSION}

The purpose of this study was to investigate the heat produced by 3 individual implant drill systems after repeated drilling including low-speed drilling technique without irrigation.

The concept of low-speed drilling has been suggested as an alternative to the conventional procedure. This technique has pros, including easy manipulation of drilling path, and cons, including longer drilling time. The strength of low-speed drilling can be easily controlled to maintain the path of drilling. Conventional drilling can change its drilling path on its own when the drill encounters a dense cortical bone. Low-speed drilling can inform the operator that the path has changed so that the operator can correct it. Ericsson and
Albrektsson ${ }^{14}$ (1983) demonstrated that heating bone to $47^{\circ} \mathrm{C}$ for $1 \mathrm{~min}$ reduced the amount of bone that grew into the implant. They established that the threshold level for bone survival during implant site preparation is $47^{\circ} \mathrm{C}$, keeping drilling time below 1 min. Bachus, et al. ${ }^{5}$ (2000) have demonstrated that through the application of a strong force to the drill, both the maximum cortical temperature above $50^{\circ} \mathrm{C}$ and its duration can be effectively reduced and subsequently decrease the potential for thermal necrosis in the neighboring cortical bone.

Multiple factors have been implicated in the production of heat during osteotomy preparation. These factors include drill speed ${ }^{9,24,25}$, cortical thickness ${ }^{3,23,27}$, drill sharpness ${ }^{1,11}$, drill force ${ }^{1,18}$, drill depth ${ }^{11}$, drill design ${ }^{11,18}$, drill diameter ${ }^{11}$, graduated compared with 1-step drilling ${ }^{11,27}$, and irrigation $6,15,22$. Bur wear has been considered as well. Chacon, et al. ${ }^{10}$ (2006) have concluded that bur wear and bur geometry play a major role in heat production. From a heat generation standpoint, Misir, et al. ${ }^{23}$ (1972) conclude that preparing an implant site with using surgical drill guides generates heat more than classical implant site preparation regardless of the irrigation type.

Bone temperature can be measured by two methods. One is the method using a thermocouple embedded in bone, and the other is infrared thermography. Thermography detects the radiant infrared value of a subject, discriminates the distribution of temperature as a visible image, and expresses it in color on a monitor. Thermography has a few advantages: its ease of use and real time measurement. Although thermography is limited in accuracy with an error of up to $\pm 1^{\circ} \mathrm{C}$, this error is 
not large enough to affect the conclusion. Infrared thermography was used in this study because the method using a thermocouple required too much effort to set up the instrument, and also because it was unclear whether this method was more accurate.

Implant site preparation techniques currently in use involve drilling at speeds of 1,000 to $1,500 \mathrm{rpm}$ to prepare potential recipient sites. The mechanical and thermal damage to the tissue surrounding the implant during drilling could have a destructive effect on the initial state of the cavity housing the implant ${ }^{19,20}$. In this study, gradual drilling caused less friction, and thus less trauma to the bone. Compared to conventional drilling, low-speed drilling took much longer duration of drilling time. A single drill with the same size ( $2 \mathrm{~mm}$ and $3 \mathrm{~mm}$ ) was used for each implant drill system except for the Brånemark system. Different Brånemark system burs with the same size were used only once according to the manufacturer's protocol, as previously reported by Chacon, et al. ${ }^{9}$ (1996). Those authors showed that temperature increases when drills were used multiple times.

Clinicians sometimes need a small amount of bone graft material during implant surgery. Some use alloplastic material and others take autogenous bone from the patient's donor site. Others have used bone was collected with new devices during surgery for bone graft. This is particularly important because clinically autogenous bone has been reported to be the ideal defect filler. Bone collected during low-speed drilling may be easier to manipulate than bone collected by other methods, such as bone trap and bone collector. The effects of drill speed on heat production have been studied to improve irrigation delivery systems ${ }^{19,20}$. The fact that the drill is used at low speeds helps improving the quality of bone obtained, as shown by light microscopic and ultrastructural analysis ${ }^{4}$, and the biological conditions of bone tissue in the new-alveolar sockets. However, this method has a disadvantage in that friction may possibly traumatize the collected bone as well as the surrounding bone because it cannot be irrigated during drilling. To prevent bone necrosis, clinicians should drill at a low speed between 20 and 100 rpm without irrigation. As the drill completes considerably more rotations at high speed than at low speed, yet advances the same distance, highspeed drilling shreds the tissue to a greater extent. The effects of drill speed on heat production have been studied to improve irrigation delivery systems ${ }^{25}$. Several authors ${ }^{8,21}$ have compared bone particles obtained from different commercial bone traps and examined differences in the percentage of bone to coagulum. Bone trap design also affects the mass and the nature of the collected tissue ${ }^{28}$. The presence of microorganisms found during the collection process can be very high due to saliva retention with some bone traps ${ }^{8}$. However, the displaced tissue retained in the drill bit during lowspeed drilling was very easy to collect, reducing saliva contamination.

In the present study, low-speed drilling without irrigation did not increase bone temperature. The small number of data included in this study limits the extrapolation of results. A randomized clinical trial comparing low-speed drilling and conventional speed drilling under controlled clinical conditions should be conducted to provide further evidence of the effect of low-speed drilling protocols. Animal studies may also be helpful in gathering histological data on bone regeneration from collected bone during low-speed drilling.

\section{CONCLUSIONS}

Within the limitations of this study, it is suggested that low-speed drilling at $50 \mathrm{rpm}$ without irrigation may not significantly increase bone temperature, and that there may be a direct relationship between bur diameter and bone temperature. This may explain why we start drilling with the smallestsized bur and increase the bur size progressively during implant surgery.

\section{REFERENCES}

1- Abouzgia MB, James DF. Temperature rise during drilling through bone. Int J Oral Maxillofac Implants. 1997;12(3):342-53. 2- Albrektsson T, Brånemark PI, Hansson HA, Lindstrőm J. Osseointegrated titanium implants: Requirements for ensuring a long-lasting, direct bone-to-implant anchorage in man. Acta Orthop Stand. 1981;52(2):155-70.

3- Alves SF, Wassall T. In vitro evaluation of osteoblastic cell adhesion on machined osseointegrated implants. Braz Oral Res. 2009;23(2):131-6.

4- Anitua E, Carda C, Andia I. A novel drilling procedure and subsequent bone autograft preparation: a technical note. Int J Oral Maxillofac Implants. 2007;22(1):138-45.

5- Bachus KN, Rondina MT, Hutchinson DT. The effects of drilling force on cortical temperatures and their duration: an in vitro study. Med Eng Phys. 2000;22(10):685-91.

6- Benington IC, Biagioni PA, Briggs J, Sheridan S, Lamey PJ. Thermal changes observed at implant sites during internal and external irrigation. Clin Oral Implants Res. 2002;13(3):293-7.

7- Benington IC, Biagioni PA, Crossey PJ, Hussey DL, Sheridan $\mathrm{S}$, Lamey PJ. Temperature changes in bovine mandibular bone during implant site preparation: an assessment using infrared thermography. J Dent. 1996;24(4):263-7.

8- Blay A, Tunchel S, Sendyk WR. Viability of autogenous bone grafts obtained by using bone collectors: histological and microbiological study. Pesqui Odontol Bras. 2003;17(3):234-40. 9- Brisman DL. The effect of speed, pressure, and time on bone temperature during the drilling of implant sites. Int J Oral Maxillofac Implants. 1996;11(1):35-7.

10- Chacon GE, Bower DL, Larsen PE, McGlumphy EA, Beck FM. Heat production by 3 implant drill systems after repeated drilling and sterilization. J Oral Maxillofac Surg. 2006;64(2):265-9.

11- Cordioli G, Majzoub Z. Heat generation during implant site preparation: an in vitro study. Int J Oral Maxillofac Implants. 1997;12(2):186-93.

12- Eriksson AR, Adell R. Temperatures during drilling for the placement of implants using the osseointegration technique. J Oral Maxillofac Surg. 1986;44(1):4-7.

13- Eriksson AR, Albrektsson T. The effect of heat on bone regeneration: an experimental study in the rabbit using the bone growth chamber. J Oral Maxillofac Surg. 1984;42(11):705-11. 14- Eriksson AR, Albrektsson T. Temperature threshold levels for heat-induced bone tissue injury: a vital-microscopic study in the rabbit. J Prosthet Dent .1983;50(1):101-7. 
15- Eriksson AR, Albrektsson T, Albrektsson B. Heat caused by drilling cortical bone: Temperature measured in vivo in patients and animals. Acta Orthop Scand. 1984;55(6):629-31.

16- Eriksson AR, Albrektsson T, Grane B, McQueen D. Thermal injury to bone: a vital-microscopic description of heat effects. Int J Oral Surg. 1982;11(2):115-21.

17- Eriksson AR, Albrektsson T, Magnusson B. Assessment of bone viability after heat trauma. A histological, histochemical and vital microscopic study in the rabbit. Scand J Plast Reconstr Surg. $1984 ; 18(3): 261-8$.

18- Harris $\mathrm{BH}$, Kohles SS. Effects of mechanical and thermal fatigue on dental drill performance. Int J Oral Maxillofac Implants. $2001 ; 16(6): 819-26$

19- Iyer S, Weiss C, Mehta A. Effects of drill speed on heat production and the rate and quality of bone formation in dental mplant osteotomies. Part I: Relationship between drill speed and heat production. Int J Prosthodont. 1997;10(5):411-4.

20- Iyer S, Weiss C, Mehta A. Effects of drill speed production and the rate and quality of bone formation in dental implant osteotomies. Part II: Relationship between drill speed and healing. Int J Prosthodont 1997;10(6):536-40.

21- Kainulainen V, Oikarinen K. Comparison of bone collectors designed for oral and maxillofacial surgery: an in vitro study. Clin Oral Implants Res. 1998;9(5):327-32.
22- Lavell C, Wedgwood D. Effect of internal irrigation on frictional heat generated from bone drilling. J Oral Surg. 1980;38(7):499503.

23- Matthews LS, Hirsch C. Temperatures measured in human cortical bone when drilling. J Bone Joint Surg Am. 1972;54(2):297308.

24- Misir AF, Sumer M, Yenisey M, Ergioglu E. Effect of surgical drill guide on heat generated from implant drilling. J Oral Maxillofac Surg. 2009;67(12):2663-8.

25- Sharawy M, Misch CE, Weller N, Tehemar S. Heat generation during implant drilling: the significance of motor speed. J Ora Maxillofac Surg. 2002;60(10):1160-9.

26- Watanabe F, Tawada Y, Komatsu S, Hata Y. Heat distribution n bone during preparation of implant sites: heat analysis by real-time thermography. Int J Oral Maxillofac Implants. 1992;7(2):212-9. 27- Yacker MJ, Klein M. The effect of irrigation on osteotomy depth and bur diameter. Int J Oral Maxillofac Implants. 1996;11(5):6348.

28- Young MP, Worthington HV, Lloyd RE, Drucker DB, Sloan $\mathrm{P}$, Carter DH. Bone collected during dental implant surgery: a clinical and histological study. Clin Oral Implants Res. 2002;13(3):298303. 